Published as: Storme, T., Beaverstock, J.V., Derudder, B., Faulconbridge, J.R., Witlox, F. (2013) How to cope with mobility expectations in academia: Individual travel strategies of tenured academics at Ghent University, Flanders. Research in Transportation Business and Management, 9, 12-20. http://dx.doi.org/10.1016/j.rtbm.2013.05.004

\title{
How to cope with mobility expectations in academia: Individual travel strategies of tenured academics at Ghent University, Flanders
}

\author{
Storme, T. ${ }^{\text {al }}$, Beaverstock, J.V. ${ }^{\text {b }}$, Derudder, B. ${ }^{\text {a }}$, Faulconbridge, J.R. ${ }^{\mathrm{c}}$, Witlox, F. ${ }^{\text {a }}$ \\ ${ }^{a}$ Ghent University, Department of Geography, Krijgslaan 281 - S8, 9000 Ghent, Belgium \\ ${ }^{b}$ University of Nottingham, School of Geography, University Park, Nottingham NG7 2RD, United Kingdom \\ ${ }^{c}$ Lancaster University Management School, Department of Organisation, Work and Technology, Lancaster LA1 \\ $4 Y X$, United Kingdom
}

\begin{abstract}
The production and exchange of knowledge are inextricably linked to different compulsions to corporeal proximity and therefore travel. As primary producers and transferors of knowledge, academics are no exception to this rule, and their compulsions seem to be further propelled by institutional discourses regarding the alleged virtues of "internationalization." Tenured academics, moreover, have a high degree of independence and can therefore easily choose how to cope with compulsions and constraints to internationalize. However, the business-travel literature has paid scant attention to academics and their individual contexts. In an effort to rectify this situation, this paper explores a travel dataset of tenure-track academics $(\mathrm{N}=870)$ working at Ghent University. The insights emerging from this analysis are then contextualized by complementing them with in-depth interviews of tenured academics $(\mathrm{N}=23)$ at the same institution. This paper argues, first, that varying compulsions and constraints at home and abroad lead to distinct non-travel and travel-intensive academic roles. And second, that academics who have difficulties coping, try to rationalize their corporeal travel behaviour and their mobility behaviour to meet the needs and expectations to internationalize. These strategies give an indication of how travel-related working practices can become more efficient and sustainable in the future.
\end{abstract}

\section{Keywords}

academic travel strategies, internationalization of higher education, business travel, virtual travel

\footnotetext{
${ }^{1}$ Corresponding author. Contact details: tom.storme@ @ugent.be, t: +329/264.47.10, f: +329/264.49.85
} 


\section{Introduction}

During the last two decades, our society has been shaped by ever-increasing and spatially extended travel, enabled, amongst other methods, by a wide array of efficient and affordable modes of transportation and communication (Urry, 2007). Extensive physical travel has thus burgeoned and evolved "from a luxury form of mobility for the wealthy few into a contemporary form of hypermobility" (Gössling \& Peeters, 2007, p.402.). Although business travel may constitute only a limited part of all corporeal mobility, being able to travel frequently has proven to be a very important asset for workers in today's globalizing economy (see Aguiléra, 2008; Millar \& Salt, 2008; Wickham \& Vecchi, 2009, 2010; Beaverstock et al., 2009; Faulconbridge et al., 2009). Many have argued that despite the various possibilities of "virtual travel" (i.e., the use of information and communication technologies), certain work practises, especially those that are informal and tacit, simply require corporeal proximity (Lassen et al., 2006; Urry, 2007; Aguiléra, 2008; Beaverstock et al., 2009; Faulconbridge et al., 2009), which Urry (2007) referred to as the "mobility burden." Therefore, employees are increasingly undertaking work outside the formal workplace (Beaverstock et al., 2009).

The compulsions to physical proximity are also evident in the knowledge-intensive academic sector, and, more specifically, in order to produce and exchange scientific knowledge (Jöns, 2008; Cantwell, 2011; Edler et al., 2011, Julsrud et al., 2012). And although more "conventional" businesses can benefit from the creation of distance, for instance, to exploit labour-cost advantages (see Millar $\&$ Salt, 2008), the emphasis in knowledge-generating institutions, by contrast, is believed to rest largely on seamless knowledge diffusion and, therefore, the creation of proximity. Moreover, since the end of the 1990s, European institutional discourses are favouring "internationalization" of the higher-education sector and, as a consequence, championing the mobility of students and staff (Ackers, 2008). Thus, the propensity and expectations to travel seem to be greater than ever for academics.

However, according to many authors, regular work-related travel is considered to be unsustainable, as it is "cursed" with high economic, ecological, and social costs (for an overview, see Beaverstock et al., 2009). Short-term academic travel is particularly undertaken by tenured staff who are embedded locally at a specific institution and are obliged to seek a suitable balance between their duties at the home institution and abroad. Moreover, a particular feature of tenure-track academics is their high degree of freedom and low degree of control (Enders, 2001; Lassen, 2006). This implies that they can, with relative ease, trade off the benefits and costs of trips and cope with changing contexts, which can lead to diverse "internationalization" strategies. Apart from the work of Lassen (2006; Lassen et al., 2009) and Ackers (2010), short-term academic travel has not yet been the subject of much scholarly attention. A better understanding of academic travel and alternative coping strategies can, however, benefit both travellers and travel management across other sectors seeking to increase their level of internationalization, while retaining sustainability both from a social and environmental point of view. 
In the heat of the institutionalized internationalization fury, this paper tries to contribute to this research hiatus by addressing the following questions: (i) How many academics actually engage in regular short-term travel? (ii) How great is the compulsion to internationalize and, hence, travel? Which travel constraints exist, and which incentives necessitate travel? (iii) How do "self-dependent" academics cope with compulsions and constraints when they are "off balance"? This paper tries to answer these questions by analysing the travel-application data of lecturers and professors $(\mathrm{N}=870)$ at Ghent University (UGent), one of the largest Flemish institutions of higher education and research. Patterns emerging from this dataset are then contextualized by complementing this information with qualitative data from 23 semi-structured interviews with tenured academic staff at the same institution.

Two key arguments are made in this paper. First, we show that the increased travel incentives lead to specific non-travel and travel-intensive roles in academia. Two travel-intensive roles stand out increasingly nowadays: (i) the role of the "project manager," managing (several) foreign research projects from project scope to evaluation, which requires regular face-to-place and face-to-time proximity (see Urry, 2007); and (ii) the role of the "research team manager," with a particular emphasis on face-to-face proximity. These managers accumulate "network capital" (Elliot \& Urry, 2010) by putting together a network of widespread contacts. They do so not only for themselves but also for the entire research group. Travel for this latter category of academics is deemed necessary to seek research funding, to set up international collaboration, to scout for talent, etc. on a global scale. Second, we argue that those academics who have difficulties coping with the compulsion to corporeal travel seem to rationalize their corporeal travel behaviour, and simultaneously their mobility behaviour, by a more-efficient choice between travel modes for distinct purposes.

\section{Internationalization and travel at Ghent University}

The empirical focus of this research is the approximately 5.500 academics working at Ghent University (UGent). This Flemish institution of higher education and research actively positions itself in the global higher-education arena: UGent was positioned 148th in the 2012 QS World University Ranking (http://www.topuniversities.com) and 89th on the 2012 Academic Ranking of World Universities (www.shanghairanking.com). Furthermore, according to its mission statement, UGent defines itself in a broad international perspective. This stems, amongst other causes, from bilateral collaboration agreements with partner countries such as China, Russia, Vietnam, and Argentina and, more recently, from opening a branch campus in Songdo, South Korea, where it offers educational programmes to students in the wider region.

Ghent University and the main government-sponsored research funding agency in Flanders (FWO) have oriented their "internationalization" strategy to the policy guidelines and directives of the European Commission towards the European Higher Education Area, where mobility "in and by itself" is heavily supported (Ackers, 2008). The main consequence of these strategies is perhaps best 
captured by the recent FWO action plan for 2012-2016: "a researcher can no longer afford himself to be immobile" (FWO, 2011). The line of reasoning behind this stimulation of mobility is that international collaboration and competition amongst academics is believed to lead to higher quality in research (see Ackers, 2008; 2010; Leemann, 2010) and to avoid scientific provinciality (Kyvik et al., 1999). As a corollary, mobility is being funded intensely through the Erasmus Exchange Programme and Erasmus Mundus, amongst others, of which UGent claims to be one of the forerunning participators.

Not unlike other institutions of higher education and research, there is no central office in charge of the travel management of UGent academics (see also Lassen, 2006). This implies that international travel is not covered by official policies or even general rules, which leaves senior academics at UGent a high degree of freedom and flexibility. Aspects of international mobility can be shaped at the level of the department and research group but are mostly determined at the individual level. We are aware that the focus on the UGent example engenders some specificity, as the institution has a particular profile in terms of travel budgets, employment structure, and workforce characteristics, but we nonetheless believe our case study allows us to tease out some more general patterns about other medium-sized European institutions of higher education and research.

\section{Data and methods}

\subsection{Quantitative data analysis}

Travel data are increasingly tracked and stored (Urry, 2007). This holds true for academic staff at Ghent University as well. Since 2009, all employees are required to register work-related journeys with at least one overnight stay in an online central-management database, mainly for reimbursement purposes. The information we have at our disposal from this dataset relates to the time period and country of destination of journeys over a two-year time span (2009-2010). Academic travel in this dataset is highly comparable to "short-term business travel," which is the shortest corporeal mobility type in the mobility portfolio of organizations, according to Millar and Salt (2008). Those journeys involve at least one overnight stay but may last up to one month (see Millar \& Salt, 2008). Of all registered trips, 97.5 percent meet these criteria, while 2.5 percent of trips last longer than one month.

For the purpose of this paper, we extracted the travel applications $(\mathrm{N}=7.388)$ of the lecturers and professors $(\mathrm{N}=870)$ because this group of senior academics share many job characteristics (i.e., relatively high levels of job security, autonomy, authority, income, etc.). Travel differences in the analyses are then expected to be independent from these job aspects. The results of the analyses will be less relevant for younger, doctoral academics, who lack a tenured position and are therefore expected to have fewer options of choice when seeking to advance up the career ladder; for them, travel may to a large extent be insurmountable. Although lecturers and professors represent only 21.8 
percent of all academics in the dataset, they account for approximately 42 percent of all travel applications. Approximately 10 percent of all lecturers and professors at UGent are not represented in the dataset. Their exclusion can be understood in two ways: either they did not travel during the two years under study, or they did not register their journeys because no reimbursement by the financial department of Ghent University was needed. Statements about the travel pattern of academics in this dataset may in the first case lead to overestimation, but they are expected to have some level of underestimation in the latter case as well.

This trip dataset was transformed into a dataset of "travelling academics." For each individual academic, we measured different aspects of travel by calculating the following, easily interpretable "travel variables": (i) total time spent abroad during the two years (in days); (ii) average time spent abroad during one trip (in days); (iii) total number of trips in a two-year period, a measurement of travel frequency; (iv) average distance travelled for a trip (in $\mathrm{km})^{2}$. These data were complemented with personal characteristics of the travellers, more specifically, two family-related characteristics (having a partner ${ }^{3}$ and/or children ${ }^{4}$ ) and two background characteristics (gender and age).

A cluster analysis allowed reducing the complexity of the dataset and, in this case, grouping similar academic travellers together in a number of clusters based on a combination of the above-described standardized travel variables. There are various algorithms to determine the homogeneity of similar cases and the heterogeneity of distinct cases. The SPSS TwoStep Cluster method (SPSS version 19) was chosen because our dataset has a relatively large number of cases $(\mathrm{N}=870)$ and contains both continuous (the travel variables) and categorical (gender, age class, family obligations) attributes. The SPSS TwoStep cluster procedure ${ }^{5}$ is more capable of handling these dataset characteristics than, for example, more traditional hierarchical or k-means cluster methods (Norusis, 2011). We chose to interpret five clusters because the clustering was characterized by a good overall goodness-of-fit (average SMCS of 0.5 ), and all travel variables contributed equally to the formation of clusters

\footnotetext{
${ }^{2}$ Because of a lack of more detailed data, distances were measured from Ghent to the destination country's centre. These are rather crude estimations, especially to large countries such as the US or China, but they still allow distinguishing between academics with a rather "local" or "global" orientation. Distances are two-way and calculated "as the crow flies" via the Google distance calculator (see http://www.daftlogic.com/projects-googlemaps-distance-calculator.htm).

${ }^{3}$ We did not distinguish between cohabiting and married academics, nor did we differentiate between unmarried and divorced academics.

${ }^{4}$ We are aware that, from a certain age, having children no longer implies much caring duties, as children leave the house. However, our data did not allow taking such differences into account.

${ }^{5}$ There are assumptions that should be met in advance to attain the best clustering results. First, the travel variables on which the clustering is based should be independent. Second, all continual travel variables are assumed to have a normal distribution, and categorical variables should have a multinomial distribution (Norusis, 2011). It is clear that the mobility variables in this analysis are to an extent related to each other. Norusis (2011) states that these two assumptions are seldom met in practice, but nonetheless, the algorithm is "thought to behave reasonably well when the assumptions are not met." Moreover, the degree to which these assumptions are met and the overall goodness-of-fit of the cluster procedure is measured by the "silhouette measure of cohesion and separation" (SMCS) and varies between -1 and 1. More specifically, a SMCS between 0.2 and 0.5 gives a fair cluster solution, while a SMCS above 0.5 indicates a good cluster quality.
} 
(minimum variable importance of 0.84 for travel variable "average time spent abroad," while the maximum importance of "average distance travelled" is 1.00).

\subsection{Qualitative data analysis}

The results of the quantitative analysis above are subsequently contextualized by means of qualitative data. Forty-five (45) invitations were sent to randomly selected heads of departments at Ghent University, asking them to take part in a semi-structured interview or to recommend another tenured academic within their department for interview participation. Between March 2010 and March 2012, 23 interviews (14 heads of department and 9 other lecturers and professors) were conducted. The intention was neither to make the sample an accurate representation of the wider academic population at Ghent University nor to select academics based on the clustering outcomes. However, by selecting heads of departments for these interviews, we assured that the respondents had already successfully achieved a senior rank in their academic careers, and that they had experienced the growing expectations to internationalize. Moreover, these academics had often established the travel policies within their departments or research groups.

\section{INSERT TABLE 1 ABOUT HERE}

The characteristics of the interview respondents are shown in Table 1. The respondents were assigned to clusters based on the first set of questions of the interview, which explored the travel behaviour of the individual respondent at the time of the interview. We interviewed more frequent-travelling academics than expected, based on the clustering outcomes, and we did not interview any academics with characteristics conforming to the fourth cluster. The next set of interview questions was structured around travel policies and the travel behaviour of academic colleagues within the research group. At the end, in-depth questions were asked about alternatives to physical mobility and the future of academic interaction. The interviews were conducted face-to-face, audio-recorded, transcribed, and analyzed in QSR NVivo 10, a software package for qualitative analyses. Nodes were created based on the themes of the questions and were added during the coding of the interviews. The quotes presented in this paper have been made anonymous in order to maintain confidentiality. Abbreviations for cluster labels can be read in Table 1.

\section{Results}

\subsection{Variations in academic travelling behaviour}

In this first part of the results section, the outcomes of the cluster analysis are explored. More specifically, we show that different work-related types of travel behaviour exist amongst our sample of academics. Cluster averages for the travel and personal variables under study are presented in Table 2, while Figures 1-4 show the cluster box plots for each travel variable separately. These visuals show 
that almost 90 percent of all lecturers and professors are to be found in the first three clusters. Clusters four and five represent a minority of travellers but have some peculiar characteristics. Each cluster has been given a label that captures the most important travel feature of its cases. The interpretation of the clusters can be summarized by discussing the following three main observations.

\section{INSERT TABLE 2 ABOUT HERE}

Observation 1: A fairly large group of academics have relatively low-travel behaviour.

Almost 30 percent of all senior academics $(\mathrm{N}=255)$ are represented by the travel behaviour of the first cluster, which could perhaps be described best as a low and local travel behaviour (ML). The cluster averages are low for each travel variable in the analysis; these academics journeyed on average merely 1.5 times a year, spent less than five days per year abroad, and travelled mainly to neighbouring countries. These lecturers and professors seem to cope with the compulsion to internationalize with the absolute minimum amount of travel, and when they do travel, they journey locally. An interpretation of the personal characteristics of the academics in this group reveals that there are more female academics represented than expected, and that a greater number of academics have a partner and/or child(ren).

The fourth cluster also consists of travellers $(\mathrm{N}=75)$ with very modest travel behaviour, but they differ from the first cluster in that these academics have undertaken at least one long-distance trip, bringing their average distance travelled above $10.000 \mathrm{~km}$. Consequently, they have spent a little more time abroad too, approximately 13 days a year. But with a travel frequency of 1.8 trips a year, this group of academics can also be characterized by a relatively low amount of travel, although with a more global orientation (MG). Slightly more male academics are represented in this group, and the individuals have considerably fewer family obligations. Taken together, there are a considerable number of tenured academics ( 38 percent) with low travel behaviour in the dataset. We expect these academics to have high obligations at (the) home (institution).

\section{INSERT FIGURES 1-4 ABOUT HERE}

Observation 2: The largest group of academics travels regularly.

The second and largest cluster ( $\mathrm{N}=373 ; 43$ percent) consists of academics spending, on average, 18 days abroad in 4.2 trips each year. They undertake trips outside Europe but do not tend to stay very long at the destination. Consequently, we will call these academics "regular travellers" (RT). The personal characteristics of the academics in this cluster are fairly close to what we expected, based on the average values of all the academics. It seems fair to state that this group of academics copes with the base expectations to internationalize by travelling regularly.

Observation 3: A small group of academics travel a lot. 
As a third and final observation, there are two clusters with considerably high travel activity, namely cluster three and cluster five. There is, however, a clear distinction between both groups of travellers. The 26 academics of the fifth cluster ( 3 percent) are characterized by a considerably high amount of time spent abroad during long-term trips, lasting on average more than 40 days each. During the two years under study, they remained abroad for more than 275 days on average. This group can therefore best be categorized as "long-term travellers" (LT). Note that not all trips lasted a long time, but at least one of the trips did. Only a limited number of senior academics belong to this cluster, as an academic with a tenured position is somehow obligated to regularly fulfil (research and teaching) duties at the home institution. There are more female academics in this group than expected, and more academics than expected have no family obligations (either a partner and/or children).

A larger group of academics (16 percent) are represented by the travel behaviour of cluster three, the cluster with the highest travel frequency (on average more than 10 trips each year) and an average total time spent abroad of almost two months a year. As their average trip duration is short, we expect this group of academics to have high obligations both at home and abroad. They will consequently be termed the "hyper-travellers" (HT). This group of frequent short-term travelling academics appears to consist predominantly of older men.

\subsection{A compulsion to internationalize? Purposes and constraints to travel}

It is clear from the cluster analysis that not all lecturers and professors travel to the same extent. This second part of the results builds on qualitative data and distinguishes the main purposes for and constraints to travel. Moreover, it attempts to offer an answer to the question of how the compulsion towards internationalization is experienced by the interview respondents.

The interviewees have mentioned several activities that can be performed at a distance and then necessitate regular travel. We have categorized them into four groups: (i) attending conferences, workshops or symposia, which are short-term (mass) get-togethers of academics who perform research in a similar area. The emphasis of these gatherings is clearly on face-to-face (F2F) proximity. Similar to the research of Lassen (2006) on academics at Aalborg University, the largest share of trips in this category is undertaken for conference travel; (ii) foreign project work, or the often labour-intensive and longer-term activities at specific places or in particular time periods. The need to travel very much derives from what Urry (2007) calls face-to-place and face-to-time proximity. The project work ranges from manual fieldwork to specific use of specialized equipment or research stays in order to study indigenous people; (iii) F2F meetings and gatherings originating from membership of an international network. Some activities and opportunities are "accessible" because the academic is part of such an international network. This includes, amongst other things, journeys to perform consultancy tasks, to give guest lectures, to be a member of the jury of a doctoral thesis defence, or to join a round-table discussion with experts; (iv) F2F meetings and gatherings in the context of the management of 
international research teams. Managing these people, whether an internationally oriented research group at the home institution or a foreign project team, necessitates regular travel.

Minimal travel

The majority of interview participants indicated that there was a travel "threshold," that is, a minimum amount of travel necessary for academics in order to be successful. The actual need did not stem from the transfer of formal knowledge during, for example, "presentation shopping" at conferences or a lecture to a critical audience. Rather, according to the majority of participants, the real compulsion to travel derives very much from building and sustaining network ties with "potential partners in future projects," as one of the respondents referred to his foreign colleagues. "You can't stay away for too long, because colleagues or friends [...] if you don't see them for five years, you no longer know them and they no longer know you. You have to maintain those contacts. And I think two years of absence is more or less the limit" (7, RT, male, early forties). This statement echoes Urry's (2007, p. 230) observation that network ties can only be sustained through periodic meetings to "cement the weak ties." This minimal amount of travel is needed to ensure the transfer of tacit knowledge or the knowhow and know-who during informal meetings (see Aguiléra, 2008; Elliott and Urry, 2010). Network activation (Elliot and Urry, 2010) can provide access to significant opportunities, from collaborating on funding proposals and publications to even-better job prospects: "My best opportunities always came via contacts on conferences [...] These are opportunities that let you grow as a researcher" (6, $R T$, male, early forties); "There are a lot of research and publication initiatives that originate from informal contacts at conferences. They never harmed my career - quite the contrary" (23, LT, male, late fifties). Moreover, not travelling to an event or meeting can involve an opportunity cost too, as it might mean losing out on potentially interesting opportunities: "With respect to the annual conference in the US, I do not have to be there, but when I don't go, it will cost me. It's not only about going, it's also about not going" (16, HT, male, late thirties).

To ensure this highly valued access to opportunities in the future, there is a consensus that academics need to be regularly "in the picture" internationally. This is especially true for younger researchers who still have to put themselves on the map and who still need to get involved in international networks. Older, experienced researchers have built strong ties over time and travel mainly in order to maintain the existing contacts. However, particularly for younger academics, networking proves to be difficult. It requires regular interaction and building up recognition. Only after a while does "the ball start rolling," and networking turns out to be much easier: The first time at a conference, it is impossible to network, because you don't know anyone. After attending the same conferences a few times, you start to know people and then it's much easier. Only after a while, it starts getting advantageous" (16, HT, male, late thirties). 
Some respondents don't believe the role of formal knowledge transfer to be relevant at all. They rarely consider listening to presentations to be of any importance, unless it is seen as efficient for evaluating the expertise, competencies, and skills of the presenter. And if they themselves present, they are well aware it is a way of being "visible." These academics see the formal practices as a way of gaining reputation, what Bourdieu (1975) called "scientific capital," and credibility within their field. They put more effort in meeting and seeing colleagues, which is, according to them, also a very active and planned activity: "When I attend a conference, I am very selective: I only go to presentations of people I want to meet afterwards. Listening to his or her presentation is then an important conversationstarter" (18, HT, male, early forties); "Eventually, you're an opportunist. When you speak to somebody, you already think in the back of your head: maybe I can use this person for something" (2, ML, male, early sixties).

However, many respondents point to obligations that limit their travel activities. First, certain work obligations at the home institution are bound to have a constraining effect on travel. A heavy teaching load, for example, makes travel difficult during the academic semester. Other academics with daily management tasks (of a department, laboratory, or clinic, for example) made it clear that their journeys were limited in the amount of time they could be absent. Second, almost all academics argued that the duties of caring for young children or elderly parents at least complicate frequent travel. Again, these obligations have an effect on the timing and duration of a trip, as the following quotes illustrate: "You will not see me travelling at the first of September" (19, HT, male, late forties); "I always try to avoid being away from home for two consecutive weekends" (20, HT, male, early fifties). Finally, some physiological characteristics can (temporarily or permanently) prevent academics from travelling, such as pregnancy, short- or long-term physical disability, or fear of flying. Moreover, a basic level of fitness is necessary for frequent short-term travel, and more specifically to cope with jetlag issues and sleep difficulties. This appears to be more worrisome for older academics.

\section{INSERT FIGURE 5 ABOUT HERE}

These constraints on frequent, short-term travel are no different from what Ackers (2008) observed when it comes to long-term academic mobility of younger researchers. Note that most constraints can be temporary or related to the life stage and/or career stage of the academic. Family obligations, for example, are highest when children are young and need the most care. Academics with older children or a retired partner, for example, can even find within their families incentives to travel again: "Since my wife can accompany me during travel, I increasingly like going on a trip" (8, RT, male, late forties). The significant effect of work and family obligations is not only clear from our qualitative analysis but also from our quantitative data. The visualisation of the departure time of trips (see Figure 5) indicates that academic travel is particularly undertaken outside teaching and holiday periods. Its peaks are in the examination months of June and September, while summer and winter breaks are 
periods of low-travel activity. Academics are, in this respect, not very different from "business class travellers" in the study of Derudder et al. (2011). Moreover, the individual and family characteristics of the academics in the clusters give an indication that academics with family obligations (both a partner and/or children) are more likely to be found in a cluster with low-travel activity (especially in terms of average duration of a trip and trip frequency), while the others are slightly better represented in the hyper-travelling cluster.

One academic mentioned the exceptional situation-in his eyes-where non-travel behaviour was not perceived to be problematic: "We have a post-doctoral researcher who doesn't travel. He doesn't want to. I asked him more than once to go and travel. He has enough money, but no interest. But the man is that good [in performing research] that others travel to him" $(9, R T$, male, late forties). In this peculiar situation, the non-travelling academic had already built up recognition by performing excellent research. A lot of the respondents, however, made it clear that traveling academics have an advantage as opposed to their non-travelling counterparts, especially when seeking international recognition: "If you want international recognition, then you need to travel. You are invited to give a lecture in Australia? Well, you have to go. [...] (If you want to do internationally oriented research and want recognition, then this involves travelling" (21, HT, male, late fifties); "The fact that you've been somewhere, gives you a kind of recognition [...]. Those who go to more conferences are doing better. Don't ask me why, but it's true in an implicit way" (16, HT, male, early thirties).

While it seems that tenure-track academics are somehow allowed to be off the radar temporarily, nontravel is believed to be especially harmful for one's career over longer periods and for untenured academics: "Today, in promotion committees, they will no longer only look how good you are in your discipline -it still is one of the conditions obviously — but they also look [at] to what extent you are active internationally. It increasingly becomes one of the preconditions" (2, ML, male, early sixties). "We are currently in a system where being away a lot is praised. You are a better researcher when you can present a semi-foreign scientific résumé. There are actually no supporting arguments for [it], but that's the label you get" (3, ML, female, late thirties). One respondent even took it one step further by explicitly stating that non-travel behaviour is problematic for all researchers: "I wouldn't say there is a status attached to being mobile, but it's a stigma when you're not" (10, RT, male, early fifties).

Although non-travelling academics are not necessarily disadvantaged and can be very satisfied with their travel behaviour, some of them express feelings of frustration and of being undervalued: "I am limited now, but when I will give up my job responsibilities-possibly next year-I will travel again, because I think it's necessary mentally [...]. The current situation can't last" (12, RT, male, early sixties); "At the university, people still perceive it as... You are inferior if you travel very little" (3, $M L$, female, late thirties). Additionally, academics who have travel constraints tend to criticize the extensive travel behaviour of some of their colleagues, thereby wondering how these academics 
manage to perform their duties at the home institution when they are constantly on the go: "In all honesty, there are people here, I can show you their files, who are solely occupied with giving lectures abroad. I always wonder: how do they still perform research? What do you sell during your speeches? Is it mostly research from a while ago then?" (2, ML, male, early sixties).

\section{Maximum travel}

At the other end of the spectrum, there are those academics travelling to a high extent. We distinguish two particular categories of travellers. First, long-term travel appears to be undertaken by younger people with few family obligations who are flexible enough to travel for longer periods abroad. The academics of the fifth cluster seem to meet most of these characteristics. Although this gathering or "discovery" of knowledge abroad has a long tradition within certain academic disciplines, only a small number of tenured academics (approximately 3 percent) are members of this group. Most of the project workers are apparently younger pre- or postdoctoral students with much less work and fewer family obligations at (the) home (institution). It cannot be ruled out, however, that many of these lengthy journeys are not registered in the central travel database because they are often not reimbursed or paid for by the home University.

Next, there are the frequent short-term travellers. As we learned from our interviews, the highest-travel compulsions are related to specific travel-intensive management duties, be they the management of (multiple) foreign project teams or the management of an internationally oriented research team at the home institution. We assume cluster three to consist mainly of this type of academic. Managing foreign (project) teams involves the entire process from project scope to project evaluation without the need to be physically present all the time. Therefore, an academic can even manage multiple foreign projects at the same time. However, these project-management tasks still require a high amount of "commuting," especially to meet the project team(s) abroad. Other hyper-travelling team managers are managing an internationally oriented research group at the home institution. Travel then becomes an activity to heighten the visibility of the research group, compete and lobby for resources, set up research collaboration abroad, scout foreign talent to join the research group, etc. It involves network activation for the benefit of the entire research team. Cantwell (2011) emphasized their role as "gatekeepers" in the global competition for talent because they try to recruit "the brightest and the best" on a global scale.

These academics are in many ways seen as the "ambassadors" of the research teams. One of the respondents, for example, mentioned that he networked for many others and thereby set up virtual meetings between persons who never spoke to each other before: "I said to my contacts in Saudi Arabia: "Look, I'm talking about what happens in these research teams, but I'm not the specialist, so I will arrange a virtual meeting. Then they can have their very technical discussion, in preparation of a first visit" (22, HT, male, early sixties). In this way, being in an international research group is 
important, but it does not imply that all members of the team need to travel continuously: "Eventually, there is a hierarchy, where everyone gives feedback to the manager, and it is this manager who travels around the world and translates the stories of his researchers. So you get another kind of role. It's a kind of... missionary, who goes to tell stories. But informed, of course. The person no longer performs research, but he transfers the knowledge of his people" (3, ML, female, late thirties). Even the nontravelling academics can thus be very "internationalized," and that is what Ackers (2008) points out when she explains the difference between "internationalization" and "mobility."

Hyper-travelling academics with too many compulsions, simultaneously at home and abroad, can become "off balance" and no longer able to meet demanding travel needs. There appears to be a very personal travel "limit," or maximum number of trips, as well. This maximum seems to be reached when people become tired of travelling: "When the "exotic" aspect of a certain destination fades away because you've been there often, then the total image is transformed, and it increasingly becomes a burden" (20, HT, male, early fifties). Another frequent-travelling respondent stated that he preferred to spend his summer holidays at home precisely because he travelled so much. Both these groups of academics are therefore more inclined to look for travel alternatives compared to those who enjoy occasional travel. This corresponds to a high extent with the research of Julsrud et al. (2012), where corporeal "travel tiredness" was the strongest motivation for using videoconference technologies.

\subsection{Searching for a balance between obligations at home and obligations away}

Some academics clearly experience difficulties coping with their obligations at home and away. Besides the obvious strategy of not meeting the demands and expectations abroad by, for example, not participating in foreign research projects, a first coping strategy seems to consist of "rationalizing" corporeal travel behaviour. However, unlike in the work of Kesselring and Vogl (2010) on business travel, the main rationale behind rationalization was not to cut costs but was simply a manner of coping with demanding individual contexts. Amongst the prime examples of rationalization of corporeal travel is limiting the duration spent abroad by eliminating leisure activities at the destination. As Lassen (2009) argues, travel—and especially conference travel—is not purely instigated from work rationales but can also involve tourism and pleasure. Conferences are often held at "exotic" destinations or in big cities in an effort to attract as many attendees as possible: "Yes, I am influenced by the destination, although at the end it does not really matter. You see the hotel and the airport, but not much of the country itself" (15, RT, female, late forties). As there is a lot of tourism involved in travelling, there is also some critique associated with this. These tourist activities at the destination, either prior to or after work, can therefore be one of the first aspects that people choose to let go. Other examples of rationalizing travel behaviour include travelling less frequently by more carefully selecting and weighing the activities abroad or combining multiple activities in time and space: You 
have to plan to see different groups of people. You have to go to a lecture where the Asians are and one which the Americans will attend. So, you have to manage to have... sort of maximum coverage" (7, $R T$, male, early forties).

Many academics also increasingly rationalize the choice of travel mode by opting for different travel modes when interaction risks being cancelled otherwise (see also Haynes, 2010) and/or the return (on investment) of a particular trip is not high enough. As one of the constrained respondents explained, email collaboration can be an even more efficient mode of interaction for specific objectives: "Much more direct communication, without the small talk, with a solid question, like: this is what I do, can you help me? [...] But it wasn't a problem at all. It is very direct and you have the feeling: we are already collaborating; eventually we were already in the next phase" (3, ML, female, late thirties). However, virtual travel between academics increasingly occurs via other practices as well, such as via closed, digital platforms, academic listservs, or Skype conferencing: "During those three months [of not travelling], I've done presentations in Jakarta, Dubrovnik, and two other places on conferences from my desk at home, via videoconferencing. I said to them: It is impossible to travel. They said: You are the keynote speaker. I say: OK, via videoconference. At three o'clock in the morning, with a shirt and my pyjamas, in front of my PC" (22, HT, male, early sixties). These Skype meetings are also increasingly used for "attending" doctoral thesis defences when members of the jury cannot make the trip in person. Thus, travel modes seem to increasingly become "tailored" to work objectives (Jones, 2003) argued.

Moreover, when an academic is unable to travel for various reasons, there are two other coping strategies worth mentioning. First, one can invite other people to travel to one's location instead: “I was thinking, I cannot make the trip myself, so I'll invite everybody here. Of course, you need some money, but $O K$, there is funding available for this and it worked out well" (3, ML, female, late thirties). Second, a constrained academic can send someone else: "There are conferences where we need to be represented, but he can't go no and I can't go. Can you present something? But this has to be discussed in the group... It's not something you can impose" (2, ML, male, early sixties).

We emphasize, as one of the respondents did, that virtual-travel practices are not merely a substitution. They do foster increased network activation, but the mere virtual network ties are not the same as those networked in person: "It's not only substitution, it's more than that, because it enables you to have more contacts, although you'll never get the maximum from those contacts, no. Because nothing substitutes for personal contact" (22, HT, male, early sixties). Moreover, these "early adopters" seem also to generate new work practices through the combined use of virtual technologies and local contacts, for example: "We organize informative, virtual sessions, where [our Chinese colleagues] can react upon to one of my longstanding, local contacts over there. There is no instant, live communication, because they will only tell you half you need to know. But let them discuss it on their 
own, and let us extract the useful information via our contact abroad-somebody who knows both cultures-then you make good use of virtual communication technologies to advance much faster in your project (22, HT, male, early sixties). Virtual interaction serves here as a way to improve the dialogue between people of different cultures and to advance much more quickly in foreign project work. Although many academics believe that virtual interaction will never be a substitute for corporeal travel because of a variety of reasons (see Faulconbridge et al., 2009), there might be more virtual travel in the future as a way to facilitate and structure these corporeal work practices.

\section{Business and management aspects of the research}

Studying this academic workforce with its high degree of autonomy sheds some interesting light on the widely documented "curse" of business travel across economic sectors (see Beaverstock et al., 2009) because academics can trade off the benefits and costs of travel. Other workers do not always have this luxury and studying them merely reveals the array of problems they face. This study, therefore, suggests that academic workers effectively handle the pressures surrounding travel, and the lessons learned from the academic case are thus more widely valuable in terms of understanding business travel across all sectors.

Although a large group of academics seem to have found a proper balance between responsibilities at home and away and, furthermore, enjoy the travel aspects of their jobs, our analysis also suggests that there are academics who are "off balance": these can be either academics who (temporarily) do not reach a "travel threshold" or academics who are above a certain "travel limit." These academics are inclined to look for alternative coping strategies by rationalizing their corporeal travel behaviour or increasingly shifting their focus to other, virtual-travel modes. When organizations or institutions are seeking more sustainable alternatives to corporeal travel in order to reduce the costs of regular corporeal travel, travel managers should focus on these two particular categories of workers and develop new practices which can be efficiently undertaken via virtual-travel modes. Although not all corporeal travel practices can be substituted with virtual travel practices, especially not when face-toplace proximity is needed, we believe that many practices concerning face-to-face proximity can increasingly be dealt with via virtual travel.

Moreover, based on the critiques raised by academics and the feelings of undervaluation noted by infrequent travellers, we argue that there is still a lot of incomprehension associated with the diverse functions of business travel. It is therefore necessary to increasingly understand and value these different roles. We stress that although there seems to be a basic obligation to travel for all academics, non-travelling behaviour is not necessarily problematic, particularly when the academic has already build strong network ties and a reputation in his or her field or is part of an internationalized research team. We also emphasize the important role of hyper-travellers and especially the managers of 
international research teams, be they foreign or home-based. These workers, amongst others duties, take care of network building for their non-travelling colleagues as well.

\section{Conclusions}

In this paper, we presented an empirical assessment of the travel strategies of tenured academics at Ghent University, derived from both quantitative and qualitative travel data. We showed first of all that the individual lecturer or professor is, to varying extents, compelled and constrained to travel, which leads to roles with diverging travel intensity in academia. We argued that some academics have difficulties coping with the compulsions abroad and are, therefore, inclined to look for alternatives to corporeal travel. Academics with too many compulsions at home and/or too many compulsions abroad seem to rationalize their individual corporeal travel behaviour by, for example, dropping the leisure aspect of trips or combining multiple purposes abroad. Simultaneously, they are on the lookout for more efficient uses of travel modes, thereby increasingly substituting inefficient travel and no travel with virtual-work practices.

Although this study has a limited scope, as it focuses only on senior academics at Ghent University, we believe this case study to be valuable more widely in terms of understanding business travel across economic sectors. Our findings may be less relevant for untenured academics, as they are less selfdependent and increasingly need network capital for career advancement. The paper did not elaborate on the geography of trips, as previously done in the study of Jöns (2008). She showed that distinct work practices have distinct global geographies. Both a focus on the travel activity of untenured academics and studying the geography of academic trips may, therefore, be interesting avenues for future research. 


\section{References}

Ackers, L., 2008. Internationalisation, mobility and metrics: a new form of indirect discrimination? Minerva 46, 411-435.

Ackers, L., 2010. Internationalisation and equality. Recherches sociologiques et anthropologiques 41(1). Downloaded from http://rsa.revues.org/189.

Aguiléra, A., 2008. Business travel and mobile workers. Transportation Research Part A: Policy and Practice 42(8), 1109-1116.

Beaverstock, J.V., Derudder, B., Faulconbridge, J., Witlox, F. 2009. International business travel: some explorations. Geografiska Annaler: Series B, Human Geography 91(3), 193-202.

Bourdieu, P., 1975. The specifity of the scientific field and the social conditions of the progress of reason. Social Science Information 16(6), 19-47.

Cantwell, B., 2011. Transnational mobility and international academic employment: gatekeeping in an academic competition arena. Minerva 49(4), 425-445.

Derudder, B., Beaverstock, J.V., Faulconbridge, J.R., Storme, T., Witlox, F., 2011.You are the way you fly: on the association between business travel and business class travel. Journal of Transport Geography 19(4), 997-1000.

Edler, J., Fier, H., Grimpe, C., 2011. International scientist mobility and the locus of knowledge and technology transfer. Research Policy 40, 791- 805.

Elliott, A., Urry, J., 2010. Mobile lives. Routledge, Oxon, pp.188.

Enders, J., 2001. Academic staff in Europe. Greenwood Press, London, pp.330.

Faulconbridge, J., Beaverstock, J.V., Derudder B., Witlox, F., 2009. Corporate ecologies of business travel in professional service firms: working towards a research agenda. European urban and regional studies 16(3), 295-308.

Fonds Wetenschappelijk Onderzoek Vlaanderen (FWO) 2011. Beleidsplan 2012-2016. Brussels, pp.127. Downloaded from http://www.fwo.be/CMSDownload.aspx?ID=db72db79-b538-4adc-8ff1f50738eff02b\&L=nl on 18 September 2012.

Gössling, S. \& Peeters, P. 2007. “It does not harm the environment!” An analysis of industry discourses on tourism, air travel and the environment, Journal of Sustainable Tourism, 15(4), 402-417. 
Gustafson, P., 2006. Work-related travel, gender and family obligations. Work, Employment and Society 20(3), 513-530.

Haynes, P., 2010. Information and communication technology and international business travel: mobility allies? Mobilities 5(4)n 547-564.

Jones, A., 2003. Management consultancy and banking in an era of globalization. Palgrave Macmillan, Hampshire and New York, pp.213.

Jöns, H., 2008. Academic travel from Cambridge University and the formation of centres of knowledge, 1885-1954. Journal of Historical Geography 34, 338-362.

Julsrud, T., Denstadli, J., Hjorthol, R., 2012. Business networking, travel tiredness and the emergent use of video conferences. International Journal of Sustainable Transportation, Published online. DOI:10.1080/15568318.2012.662580.

Kesselring, S., Vogl, G., 2010. '...Traveling, where the opponents are': business travel and the social impacts of the new mobilities regimes. In: Beaverstock, J. V., Derudder, B., Faulconbridge, J., Witlox, F. International Business Travel in the Global Economy. Ashgate, London, pp. 145-162.

Kyvik, S., Karseth, B., Remme, J.A., Blume, S., 1999 International mobility among Nordic doctoral students. Higher Education 38, 379-400.

Lassen, C. (2006) Aeromobility and work. Environment and Planning A, 38, 301-312.

Lassen, C., 2009. Networking, knowledge organizations and aeromobility. Geografiska Annaler: Series B, Human Geography 91(3), 229-243.

Lassen, C., Laugen, B.T., Næss, P., 2006. Virtual mobility and organizational reality - a note on the mobility needs in knowledge organizations. Transportation Research Part D 11, 459-463.

Lassen, C., Smink, C.K., Smidt-Jensen, S., 2009. Experience spaces, (aero)mobilities and environmental impacts. European Planning Studies 17(6), 887-903.

Leemann, R.J., 2010. Gender inequalities in transnational academic mobility and the ideal type of academic entrepreneur. Discourse: Studies in the Cultural Politics of Education 31(5), 605-625.

Millar, J., Salt, J., 2008. Portfolios of mobility: the movement of expertise in transnational corporations in two sectors - aerospace and extractive industries. Global Networks 8(1), 25-50.

Norusis, M., 2011. IBM SPSS Statistics 19 Statistical Procedures Companion. Pearson Education, pp.672. 
Urry, J., 2007. Mobilities. Polity Press, Cambridge, pp. 336.

Wickham, J., Vecchi, A., 2009. The importance of business travel for industrial clusters - making sense of nomadic workers. Geografiska Annaler: Series B, Human Geography, 91, 245-255.

Wickham, J., Vecchi, A., 2010. Hierarchies in the air: varieties of business air travel. In: Beaverstock, J. V., Derudder, B., Faulconbridge, J., Witlox, F., International Business Travel in the Global Economy. Ashgate, London, pp. 125-143. 


\begin{tabular}{|c|c|c|c|c|c|}
\hline & All & Cluster 1 & Cluster 2 & Cluster 3 & Cluster 5 \\
\hline \multirow[t]{2}{*}{ Cluster name } & & $\begin{array}{c}\text { Minimal } \\
\text { travel - } \\
\text { local }\end{array}$ & $\begin{array}{c}\text { Regular } \\
\text { travel }\end{array}$ & $\begin{array}{c}\text { Hyper- } \\
\text { travel }\end{array}$ & $\begin{array}{l}\text { Long- } \\
\text { term } \\
\text { travel }\end{array}$ \\
\hline & & ML & RT & HT & LT \\
\hline Total number of respondents & 23 & 4 & 11 & 7 & 1 \\
\hline$\%$ & 100 & 17,4 & 47,8 & 30,4 & 4,3 \\
\hline \multicolumn{6}{|l|}{ Work characteristics } \\
\hline Head of department & 14 & 2 & 8 & 4 & \\
\hline \multicolumn{6}{|l|}{ Personal characteristics } \\
\hline Gender & $5 \mathrm{~F} 18 \mathrm{M}$ & $2 \mathrm{~F} 2 \mathrm{M}$ & $3 \mathrm{~F} 8 \mathrm{M}$ & $7 \mathrm{M}$ & $1 \mathrm{M}$ \\
\hline Partnering & $4 \mathrm{~F} 16 \mathrm{M}$ & $2 \mathrm{~F} 2 \mathrm{M}$ & $2 \mathrm{~F} 8 \mathrm{M}$ & $5 \mathrm{M}$ & $1 \mathrm{M}$ \\
\hline Parenting & $4 \mathrm{~F} 17 \mathrm{M}$ & $2 \mathrm{~F} 2 \mathrm{M}$ & $2 \mathrm{~F} 8 \mathrm{M}$ & $6 \mathrm{M}$ & $1 \mathrm{M}$ \\
\hline \multicolumn{6}{|l|}{ Age class } \\
\hline $31-35$ & 1 & & & 1 & \\
\hline $36-40$ & 5 & 2 & 2 & 1 & \\
\hline $41-45$ & 6 & & 4 & 2 & \\
\hline $46-50$ & 2 & & 2 & & \\
\hline $51-55$ & 3 & 1 & 1 & 1 & \\
\hline $56-60$ & 3 & & 1 & 1 & 1 \\
\hline $61-65$ & 3 & 1 & 1 & 1 & \\
\hline
\end{tabular}

Table 1: Characteristics of the interview respondents ( $F=$ female; $M=M a l e)$. Source: Authors 


\begin{tabular}{|c|c|c|c|c|c|c|}
\hline & All & Cluster 1 & Cluster 2 & Cluster 3 & Cluster 4 & Cluster 5 \\
\hline Cluster name & & $\begin{array}{c}\text { Minimal } \\
\text { travel - } \\
\text { local }\end{array}$ & $\begin{array}{c}\text { Regular } \\
\text { travel }\end{array}$ & $\begin{array}{c}\text { Hyper- } \\
\text { travel }\end{array}$ & $\begin{array}{c}\text { Minimal } \\
\text { travel - } \\
\text { global }\end{array}$ & $\begin{array}{c}\text { Long-term } \\
\text { travel }\end{array}$ \\
\hline Total number of travellers & 870 & 255 & 373 & 141 & 75 & 26 \\
\hline$\%$ & 100 & 29.3 & 42.9 & 16.2 & 8.6 & 3.0 \\
\hline \multicolumn{7}{|l|}{ Travel variables } \\
\hline Average Duration Abroad (days) & 5.8 & 3.2 & 4.6 & 6.0 & 7.4 & 41.8 \\
\hline Total Duration Abroad (days) & 46.5 & 9.4 & 36.4 & 108.7 & 26.0 & 277.8 \\
\hline Average Distance travelled $(\mathrm{km})$ & 5,074 & 1,719 & 5,377 & 5,167 & 13,684 & 8,176 \\
\hline Travel frequency (trips in 2 years) & 8.5 & 3.1 & 8.3 & 21.3 & 3.6 & 8.1 \\
\hline \multicolumn{7}{|l|}{ Personal characteristics } \\
\hline Gender (\% Male) & 80.3 & 72.5 & 81.8 & 90.8 & 84.0 & 69.2 \\
\hline Partnering (\%) & 76.4 & 79.2 & 78.8 & 75.9 & 65.3 & 50.0 \\
\hline Parenting (\%) & 77.6 & 82.4 & 79.4 & 75.9 & 62.7 & 57.7 \\
\hline Age & 47.9 & 49.0 & 46.9 & 49.5 & 46.7 & 46.5 \\
\hline
\end{tabular}

Table 2: Cluster averages for all travel variables and personal characteristics of the travellers during the period under study (2009-2010). Source: Authors. 
Fig. 1: Cluster box plots for travel variable "travel frequency". Outliers excluded. Source: Authors.

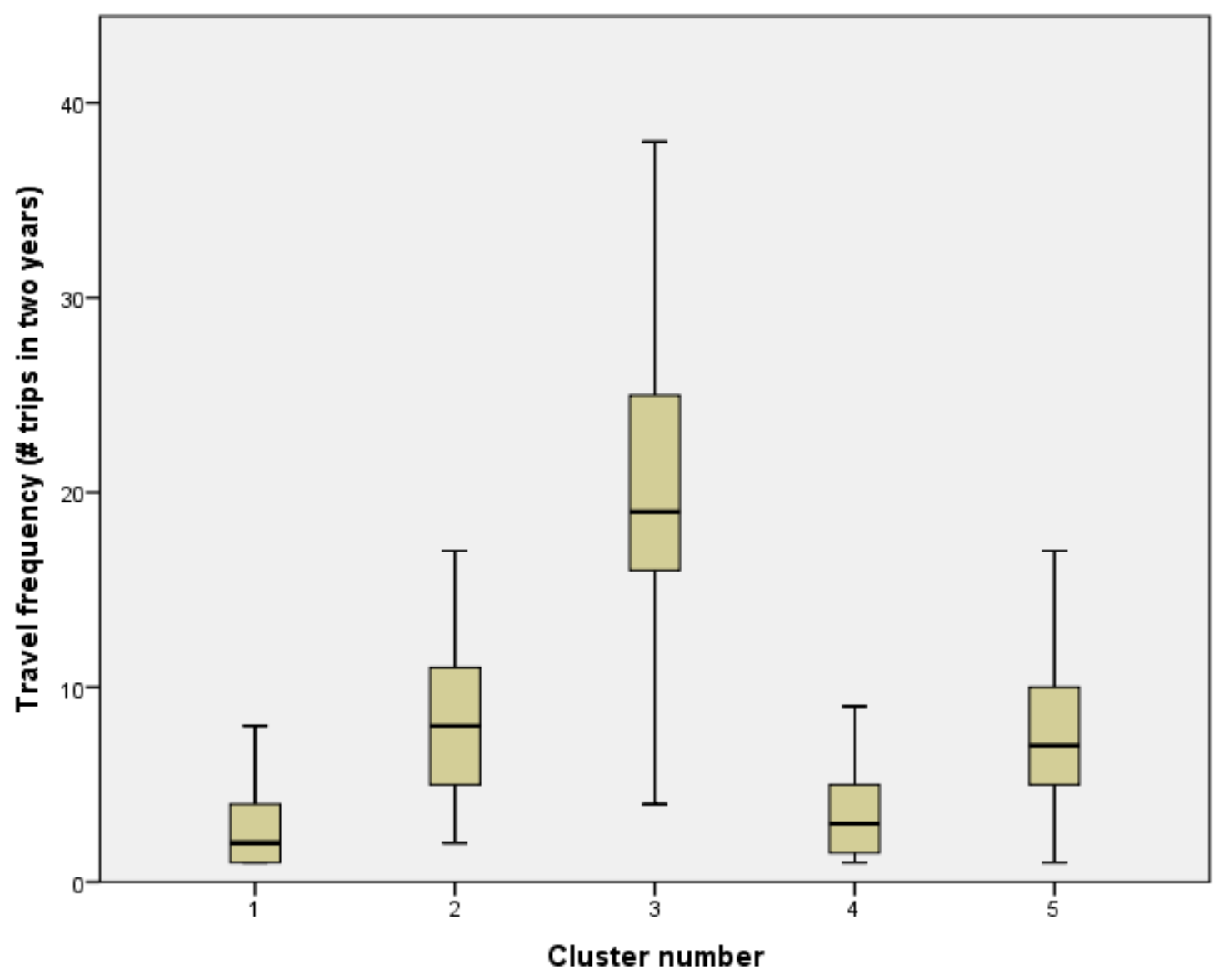


Fig. 2: Cluster box plots for travel variable "total time spent abroad". Outliers excluded. Source: Authors.

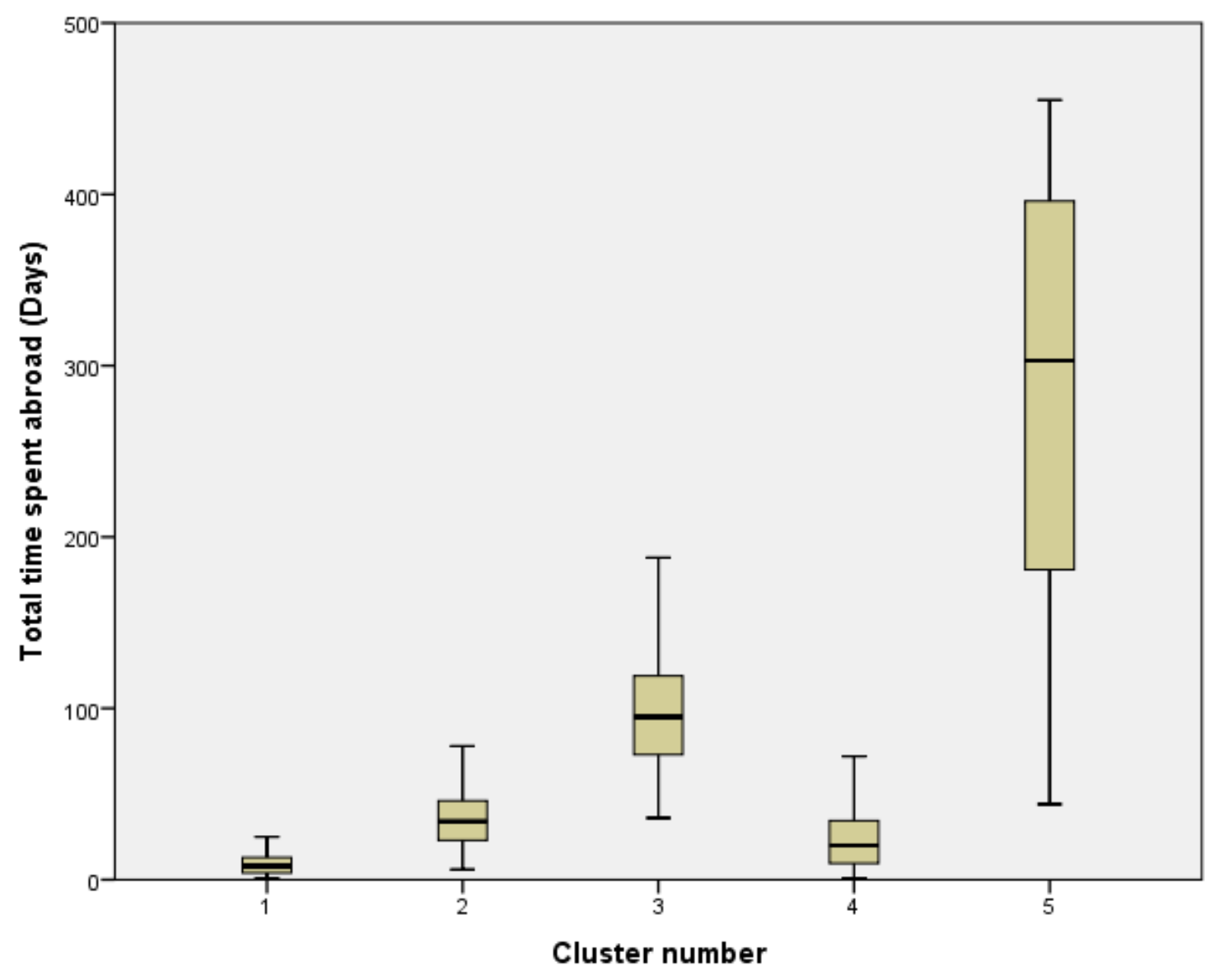


Fig. 3: Cluster box plots for travel variable "average distance travelled". Outliers excluded. Source: Authors.

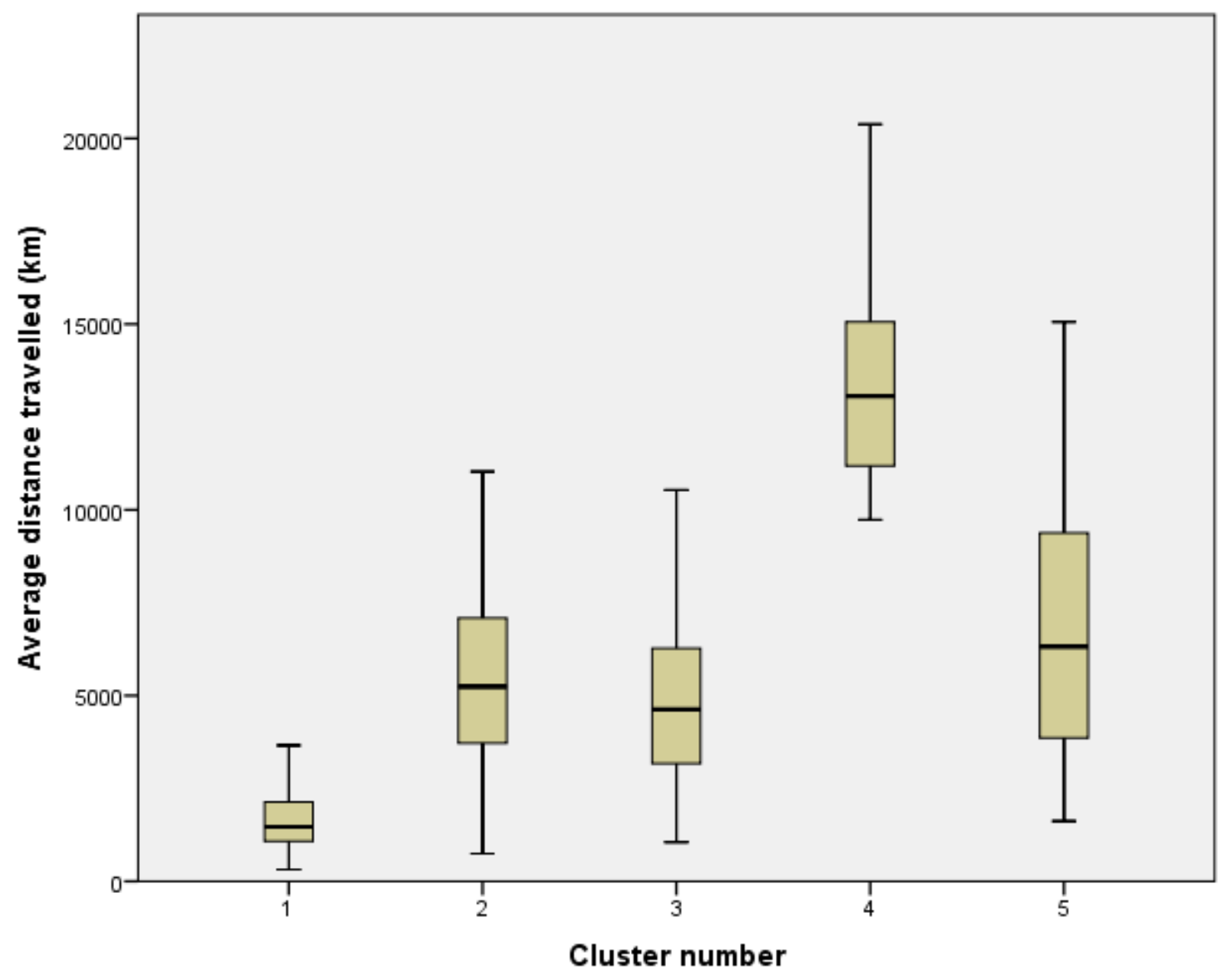


Fig. 4: Cluster box plots for travel variable "average time spent abroad". Outliers excluded. Source: Authors.

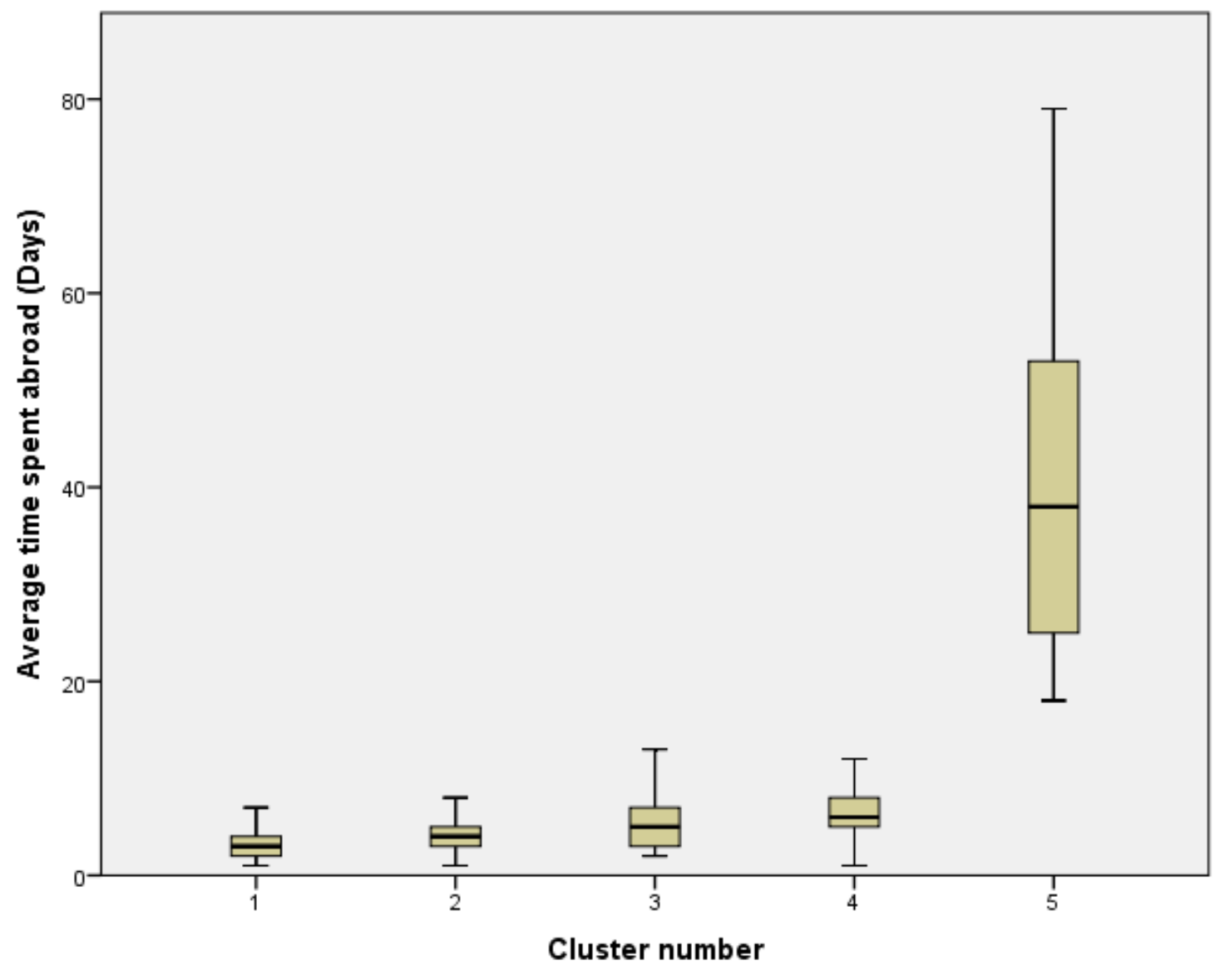


Fig. 5: Seasonal variation of departure time of journeys of UGent lecturers and professors. Source: Authors.

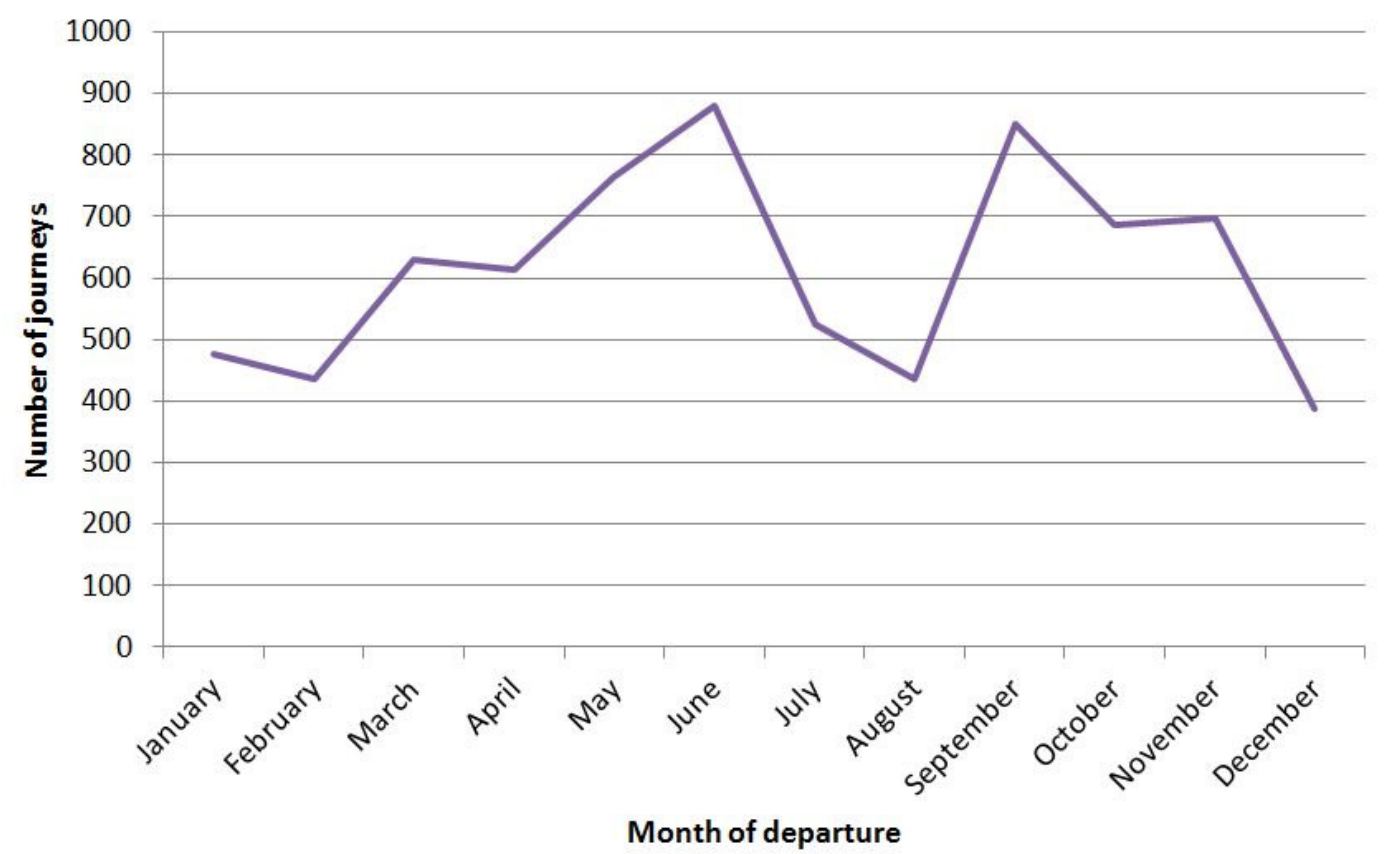

